\title{
RESEARCH ON DATA MANAGEMENT MODEL OF NATIONAL DEFENSE MOBILIZATION POTENTIAL BASED ON GEO-SPATIAL FRAMEWORK
}

\author{
LI Guoming1* , CHEN Yanmin'², YING Guowei ${ }^{1}$, WU Xiaoping ${ }^{3}$ \\ ${ }^{1}$ The Sixth Landforms Surveying Team of SBSM/Sichuan Third Surveying and Mapping Engineering Institute, Chengdu, China \\ 2.National Defense Mobilization Committee of Sichuan Province. \\ ${ }^{3}$ Sichuan Normal University, Chengdu, China. \\ *Corresponding author E-mail: li-guoming@foxmail.com, 331293996@qq.com
}

This is an open access article distributed under the Creative Commons Attribution License, which permits unrestricted use, distribution, and reproduction in any medium, provided the original work is properly cited.

\section{ARTICLE DETAILS}

\section{ARTICLE HISTORY:}

Received 12 August 2016

Accepted 12 December 2016

Available online 10 January 2017

\section{KEYWORDS:}

geographical spatial framework national defense mobilization potential; spatial data; management mode

\section{ABSTRACT}

At present, the national defense mobilization potential data is mainly unstructured data composed of text, images, report forms, lacking space attribute and location information. Therefore, a large study of national defense mobilization potential database has focused on data collection, reporting and information system construction, etc. To solve national defense mobilization potential data application problems in the construction of informatization, taking advantage of the characteristics of geographical spatial framework, this paper discusses national defense mobilization potential data management model based on geographical spatial framework.

\section{INTRODUCTION}

National defense mobilization refers to the emergency measures taken $b$ $\mathrm{y}$ the state, from peacetime to wartime, and unified mobilization of man power, material and financial resources to provide services for the war [1]. At present, Although our country has already formed the unique mobilization theory, rules and mechanisms, and established the corresponding institutional framework and the methods of implementation, it is still keep the traditional static, passive mobilization mode, the way of database storage is given priority to two-dimensional table, so space utilization rate is not enough to meet the needs of precise mobilization, and it's bad defects has increasingly visible [2,3].GIS technology with its powerful spatial data processing analysis ability and the space visual effect, in the field of national defense mobilization function has been gradually revealed. So, providing technical support to establish a defense mobilization potential database which closely related to spatial location of national and strengthening the national defense mobilization management information and intelligent level are also particularly important to carry out the national defense mobilization potential research.

\section{RESEARCH SIGNIFICANCE}

2.1 New data management model is the necessary basis to accelerate the construction of the national defense mobilization information level

Since the eighteenth congress, the central military commission President $x i$ jinping proposed defense mobilization on several occasions, and emphasized the statement which said, "firmly promoting national defense mobilization with each direction and each field" [4]. National defensemobilization preparation is the important measure to condense economic and social resources, stem and win the war; is the overall military construction and use, realize China's dream of weaponry foundation engineering. But due to multiple aspects of reasons such as the policy and financial resources, system and technical, the overall level of China's national defense mobilization preparation is still very low, and all sorts of both operational and mobilization demand hard software construction seriously lags the economic development. Especially the spatial information that support the national defense mobilization command communication and the ability of data security, the capacity of resisting disturbance with communication equipment in troops and ability to adapt to the complex battlefield and harsh environment, basic it is in a state of absence [5].

The existing national defense mobilization potential information only own potential numbers but no ability to evaluate, or focus on human, mechanical means without information intelligent matching, can't realize the mobilization preparation work and locate the precise positioning of the construction of national defense, unable to reach a quick, efficient, accurate data in national defense mobilization potential. Information is the core and essence of revolution in military affairs with Chinese characteristics, is also a strategic move in covering defense mobilization construction and development. Therefore, it is necessary to make the defense mobilization information construction as the goal and carry out with geospatial framework in the relevant technical standard system for the support of the national defense mobilization potential method for building a spatial database research.

\subsection{New data management model is the realistic demand of} improving the national defense mobilization precision level

Precision is the inevitable result of the digital, networked, intelligent and integration, is the basic goal of national defense mobilization information. The national defense mobilization precision is a process which effective use of all kinds of information technology and information means accurate prediction, analysis and grasp the mobilization demand, meticulous investigation, analysis, and grasp the national defense 
mobilization potential and precise control, allocate and optimize the combination of various kinds of mobilization resources, thus achieve join each other and dynamic balance between mobilization demand and supply.

It is an important task to strengthen the national defense mobilization potential database, standardize the technical standards and realize the precision of national defense mobilization work. According to the precision requirement of the construction of national defense mobilization, according to universal, standardized, systematic, modular and network, gradually unify the national defense mobilization information construction requirements and software standard, in particular, we should step up efforts to improve the technical standards for information applications. Based on the geospatial framework of national defense mobilization potential database construction, to establish all kinds of mobilized resources of geographical space, and other basic information items encoding standards, classification and codes of the army and national defense mobilization related information, and gradually realize the harmony and unity in the standard, has an important role to achieve accurate convergence of military demand and supply mobilization in order to improve the precision level of mobilization, and create favorable conditions.

\subsection{The new data management model is a necessary condition to effectively serve the visualization of national defense mobilization potential space}

Computers have been used for scientific computing and data processing for 50 years. However, for a long time, due to the limitations of computer technology, data can only be processed by batch instead of interactive processing. The calculation process can not be intervened and guided, but only passively wait for the output of the calculation results. While a large number of output data can only manually, or use the plotter output twodimensional graphics, the overall concept not only can not be timely visual images and related data, but also caused the loss of large amounts of information. In recent years, because of the computer soft hardware performance improvement, continuous improvement of the spatial database building method, graphics and image processing algorithms, making use of spatial data visualization technology, display the data and information become possible, andinteract. Therefore, the construction of the national defense mobilization potential spatial database can effectively get rid of the restrictions of the traditional twodimensional graphics, and solve the problem that the current national defense mobilization potential data display effects are not visual, not vivid and the amount of information is not rich.In summary, geospatial framework is the basis of geographic information resources and the acquisition, processing, storage, distribution and service management relates to the policies and regulations, standards, technology, facilities, mechanism and human resources in general, is a spatial information infrastructure, public service oriented, composed of basic geographic information data system, data directory and exchange system, policies and regulations and standards system, organizational system and public service system etc. The construction of national defense mobilization potential spatial database, requiring geospatial framework of the related technical standard system construction method as a support, realizing the information, precision and intelligent service of national defense mobilization potential data. And it is the basic and important work of civil military integration.

\section{CHARACTERISTICS OF GEOGRAPHICAL SPATIAL FRAMEWORK}

The geo-spatial framework provides a unified spatial positioning benchmark for spatial and non-spatial information, in order to achieve integration of all kinds of information according to standards, and its function includes the following three aspects [6]:

a) Geospatial framework data constitude the most basic spatial data sets in the real world, and it can completely describe the natural, social and cultural forms of topography, geomorphology, social economy and its basic characteristics. Mainly used for people study and understand the basic conditions nature to provide information support

b) The development of smart city, digital city, and all kinds of information system construction, need the most basic spatial data set as a basic support, however, these data sets are mainly extracted from geospatial framework data; c) The qualitative description, quantitative and positioning analysis is the core content of information construction, most of the thematic information itself does not have the location feature. As a reference benchmark, geo-spatial frames provide special information related to spatial location for all types of users to meet the requirements of location and quantitative processing.

To this end, geospatial data framework mainly has the following characteristics:

a) Data is rich in information, fast updating, high resolution, large amount of information, long production cycle, and high cost;

b) Because of the rapid development and rapid change of information society, the aging of information is fast and the cost of updating is high;

c) The spatial position information and the attribute information are more easily accepted, therefore,

digital line drawing DLG, digital elevation model DEM and digital orthophoto map DOM, digital raster graph DRG and other 5D products are the main forms of information.

Through the study of the geospatial framework, this study can promote the integration and sharing of the potential information of national defense mobilization, and provide an important data base for the construction of national defense information.

\section{MANAGEMENT MODEL OF POTENTIAL DATA FOR NATIONAL DEFENSE MOBILIZATION}

The current national defense mobilization potential data management is the main way to solve any problem, data storage more confusion, lack of coordination,multisource data fusion,there is no topological relatio $\mathrm{n}$, spatial information expression is not accurate,further is lack of spatial analysis function. Generally speaking, it mainly includes t he following management models:

\subsection{File management model}

Graphical data and attribute data for the potential of national defense mobilization are organized in a certain format, and the graphic elements are connected with the attribute records through the fields. The advantages of the file management data is flexible, one drawback is that data is huge, the number of data files is even tens of thousands, the efficiency of data management efficiency and information utilization is limited, andit is difficult to update, on the other hand, is not conducive to collaborative organization, filing data is very difficult to achieve record level and entity level data locking operation conflict also, the security of the data mainly depends on the operating system to ensure that data is not up to the requirements to ensure the legitimate use of. This approach is far from meeting the reliability of mobilization, especially for potential data on national defense mobilization.

\subsection{Database management mixed mode}

Graphical data for defense mobilization potential are managed by file, while attribute data is managed through large commercial databases. Among them, spatial data is managed by file, time data is structured, database is used to manage, non-spatial attribute data is managed by database. This method overcomes the problems of efficiency, security and sharing of attribute data management, improves system efficiency, and at the same time, it is easy to integrate management with information system based on text numeric data. But this way is still in the form of files or file on the spatial data management and the form of improving management through the library, while improving the management efficiency, but still can not solve the structural nature of the defect data model file.

\section{RESEARCH ON POTENTIAL DATA MANAGEMENT OF NATIONAL DEFENSE MOBILIZATION BASED ON GEOGRAPHICAL SPATIAL DATA FRAMEWORK}

National defense mobilization potential is based on future informatization under the condition of local war and carry out diversified military tasks co mmand and decision. Geospatial framework technology mainly to solve th e current situation of China's national defense mobilization potential data space is low, efficiency is not high, poor visual effect, organizational manag ement and update methods lag, improve the national defense mobilization informationization level. To this end, the main management model can be used in the following two: 


\subsection{File management model}

Full relational spatial database management refers to the management of graphical and attribute data using relational database management systems (RDBMS). In this management method, the spatial coordinate data of indefinite length is managed by relational database in the form of binary data block. In other words, coordinate data is integrated into RDBMS to form spatial database. RDBMS software vendors do not make any expansion, and are developed by GIS software vendors, which can not only manage structured attribute data, but also manage unstructured graphical data. At present, both in theory and relational database tools have been mature, andthey provide a uniform access interface (SQL) with massive data distribution operation, and it can support multiuser concurrent access, security control and consistency ch ck. But based on GIS technology, due to the indefinite length of geometric coordinate data, the storage efficiency of the whole relational spatial database management is slightly lower.

\subsection{Object-oriented spatial database management model}

Object oriented spatial database management can extend object data types to support spatial data, including point, line, polygon geometry, and allows you to define the basic operation for these geometries, including the calculation of distance, spatial relationship detection, even slightly complicated operations, such as buffer calculation, superposition model etc.it can also be seamlessly supported by object database management systems. In this way, it provides a consistent access interface for various data and part of the space model services, by the object database management system, it not only has been achieving data sharing and service space model can be sharedalso, the national defense mobilization system development can focus on the representation of data and complex professional model.

\subsection{Design principle of potential database for national defense mobilization based on geo-spatial framework}

The national defense mobilization potential database will include geographic information data (vector data, raster data and thematic data etc.) and thematic data (military information, such as traffic readiness, economic mobilization, data transmission and exchange, social resources, information, armed forces, equipment and so on).In order to make all kinds of information resources access each other through the interface module, the storage unit should be unified coordinate system, the establishment of a unified and naming rules, using the data element

classification code and symbolic rules reasonably, ensure data quality, realize the connection between the data,and keep updating the database.The data organization of data should follow the combination of progressiveness and practicability, combination of standardization and compatibility, combination of safety and maintainability, combination of centralized management and decentralized management.It should also be compatible with vector data, raster data, multimedia data, text, table data, and other data mobilization formats. At the same time, the database should have an effective backup mechanism.

\section{CONCLUSION}

The current national defense mobilization potential data management mainly adopts documents management and file database mixed management mode, data redundancy, low availability and low safety of many shortcomings, and it is far from meeting the needs of modern national defense information. Based on the geo-spatial framework technology, the database of national defense mobilization potential is managed, and the geospatial data is linked with the mobilization potential the attribute data.Thus the potential information can be displayed intuitively on the map, and it is directly applied to the national defense mobilization potential system for interactive inquiry and accurate mobilization command,and it plays an important role in enhancing the management and informatization of national defense mobilization.

\section{ACKNOWLEDGEMENTS}

Thanks are due to colleagues for assistance with soft science research project support of sichuan province, China (NO. 2017ZR0123, 2017ZR0122)

\section{REFERENCE}

[1] Zou, S.M. 2012. China's construction of national defense mobilization system with characteristics of military and civilian integration. Science and Technology Progress and Policy, 29, 31-36. DOI: 10.3969/j.issn.10017348.2012.02.008

[2] Qu, X.Y. 2014. The system of mobilization ability construction lead defense mobilization innovation and development. National Defense, 10,19-22 DOI: 10.15969/j.cnki.11-2770/e.2014.10.009

[3] Xu, K. 2016. Practice and Exploration in the Building of National Defense Mobilization System of New China. Contemporary China History Studies, 13 ,29-36. DOI: 10.3969/j.issn.1005-4952.2006.01.004.

[4] Zhong, W., and Xie, Q. 2015. Promote the development of our national defense mobilization construction innovation. National Defense, 10, 45-46. DOI: $10.3969 /$ j.issn.1002-4484.2015.10.022

[5] Rao, N., and Cheng, K.L. 2016. Defense mobilization big data application prospect and countermeasures. National Defense, 11,31-33. DOI: 10.3969/j.issn.1002-4484.2016.11.011

[6] Chen, J. 2002. Developing Dynamic and Multi-Dimensional Geo-Spatial Data Framework. Geo-Information Science, 4,7-13. DOI: 10.3969/j.issn.1560-8999.2002.01.004 